\title{
Abundance and Sexual Size Dimorphism of the Giant Gartersnake (Thamnophis gigas) in the Sacramento Valley of California
}

\author{
Glenn D. Wylie, ${ }^{1}$ Michael L. Casazza, Christopher J. Gregory ${ }^{2}$ and Brian J. Halstead
}

\section{U.S. Geological Survey, Western Ecological Research Center, 6924 Tremont Road, Dixon, California 95687 USA}

\begin{abstract}
Aвstract.-The Giant Gartersnake (Thamnophis gigas) is restricted to wetlands of the Central Valley of California. Because of wetland loss in this region, the Giant Gartersnake is both federally and state listed as threatened. We conducted mark-recapture studies of four populations of the Giant Gartersnake in the Sacramento Valley (northern Central Valley), California, to obtain baseline data on abundance and density to assist in recovery planning for this species. We sampled habitats that ranged from natural, unmanaged marsh to constructed managed marshes and habitats associated with rice agriculture. Giant Gartersnake density in a natural wetland (1.90 individuals/ha) was an order of magnitude greater than in a managed wetland subject to active season drying ( 0.17 individuals/ha). Sex ratios at all sites were not different from $1: 1$, and females were longer and heavier than males. Females had greater body condition than males, and individuals at the least disturbed sites had significantly greater body condition than individuals at the managed wetland. The few remaining natural wetlands in the Central Valley are important, productive habitat for the Giant Gartersnake, and should be conserved and protected. Wetlands constructed and restored for the Giant Gartersnake should be modeled after the permanent, shallow wetlands representative of historic Giant Gartersnake habitat.
\end{abstract}

The number of individuals in a population is a very basic demographic parameter but is difficult to measure for many species. The imperfect detectability of most animal species renders simple counts inadequate for assessing population size (Mazerolle et al., 2007), and snakes in particular have proven difficult to sample because they are inconspicuous, have extended periods of inactivity, often exist at low densities, and frequently exhibit extensive and irregular movements (Parker and Plummer, 1987). In addition to counting the number of individuals in a population, difficulties frequently arise in determining the physical boundaries of the sampled area and, therefore, the density of the population (Royle and Young, 2008). Despite these difficulties, data on population density and structure are valuable for both basic and applied studies of snake population ecology.

The Giant Gartersnake (Thamnophis gigas) is an aquatic snake restricted to wetlands of the Central Valley of California. It once ranged from Butte County in the north to Buena Vista Lake in Kern County in the south (Fitch, 1940; Hansen and Brode, 1980). Over 95\% of original wetlands in the Central Valley have been lost and the remaining habitat fragmented (Frayer et

\footnotetext{
${ }^{1}$ Corresponding Author. E-mail: glenn_wylie@ usgs.gov

2 Present address: 12 Beatty Street, Southport, Queensland, 4215, Australia
}

al., 1989). Because of this habitat loss, the Giant Gartersnake is federally and state listed as threatened. The federal listing gave this species a recovery priority number of $2 \mathrm{C}$ : full species, high degree of threat, and high recovery potential (U.S. Fish and Wildlife Service, 1993, 1999).

Little quantitative information existed on the Giant Gartersnake prior to its listing. To aid in the recovery of the Giant Gartersnake, we examined its population size and structure at four sites in the Sacramento Valley (northern Central Valley), California. In particular, we examined density and morphology of the Giant Gartersnake in wetlands of varying degrees of disturbance, from a natural, unmanaged marsh to rice agriculture. We hypothesized that the natural wetland would have the greatest density of the Giant Gartersnake and that individuals at this site also would have the greatest body condition. Conversely, we hypothesized that the site consisting of rice agriculture would have the lowest densities and body condition. We also assessed the consequences of different sampling assumptions when examining densities across populations.

\section{Materials and Methods}

We surveyed for the Giant Gartersnake during different time periods in four areas of the Sacramento Valley (Fig. 1): Badger Creek Wetlands in southern Sacramento County (March to October 1997), Gilsizer Slough in 


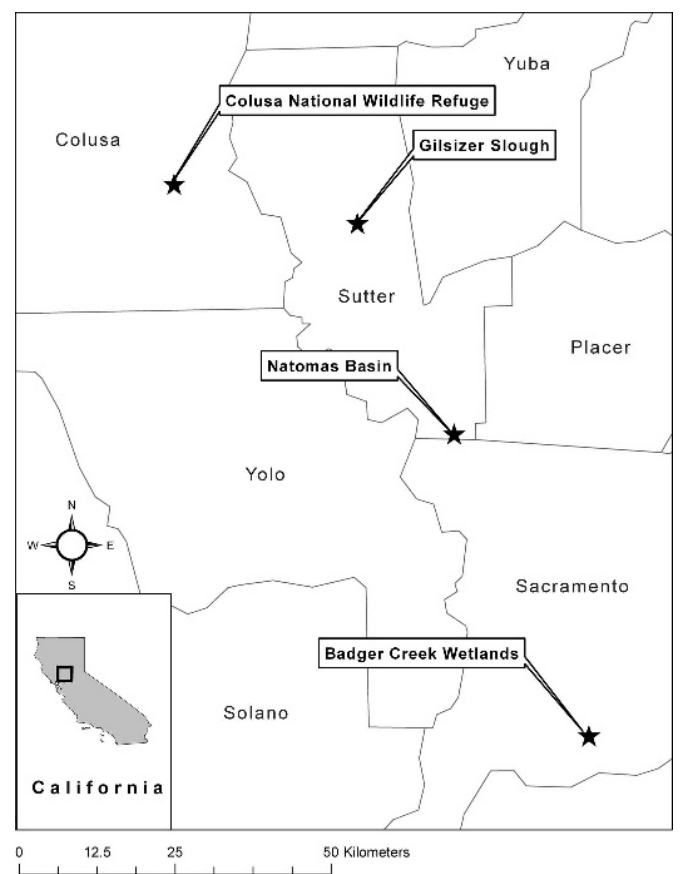

FIG. 1. Location of Giant Gartersnake study sites in the Sacramento Valley, California. Lines and names indicate county boundaries and names, respectively.

Sutter County (March to August 1996), Colusa National Wildlife Refuge (NWR) in Colusa County (March to October 1997), and the Natomas Basin in northern Sacramento and southern Sutter counties (April to August 1999). Although sampling occurred at different times at these sites, weather conditions were similar across years, and site conditions did not appreciably change at any of the sites between 1996 and 1999. These areas represent a range of habitat from unmanaged natural marsh (Badger Creek) to managed seasonal marsh (Colusa NWR) to rice agriculture (Natomas Basin). The Badger Creek Wetlands are a 240-ha series of naturally occurring, shallow wetlands at the confluence of Badger Creek and Willow Creek, tributaries of the Cosumnes River. Badger Creek was the least disturbed site and likely most closely resembled historic Giant Gartersnake habitat. Gilsizer Slough is a remnant drainage feature of the Yuba River now surrounded by farmland and bisected by the Sutter Bypass floodway. The slough itself is a natural wetland, but agricultural fields are located immediately adjacent to the slough boundary, and the slough has been modified for use as both a drain and a source of water for a network of agricultural (rice, tomatoes, melons, and orchards) irrigation ditches. Our studies were in and around the slough in a 1,400-ha section east of the east
Sutter Bypass levee. Colusa NWR is a complex of uplands, seasonal and permanent wetlands, and irrigation ditches surrounded predominantly by rice agriculture. Much of Colusa NWR was formerly agricultural fields but has largely been restored to wetlands managed for multiple species; at the time of our study, it was managed primarily for remnant rare habitats, such as vernal pools, and wintering waterfowl habitat. We studied snakes on approximately 4,500 ha in and around the refuge. The Natomas Basin is a 21,600 -ha area comprised mainly of rice agriculture (at the time of our study). The Natomas Basin was the most disturbed of our study sites, having little habitat that resembled natural wetlands. Our studies included rice fields and adjoining ditches in the east central part of the basin and Fisherman's Lake, a remnant slough channel of the Sacramento River surrounded by rice fields.

Individuals were either caught by hand during visual searches or with modified floating minnow traps (Casazza et al., 2000). Traps were placed along the edges of ditches and vegetation-water edges in transects of 10-50 traps placed at a spacing of approximately $10 \mathrm{~m}$. Trapline locations were selected based upon the presence of adequate water for the traps to float (minimum of $10 \mathrm{~cm}$ ) and the presence of bank or vegetation edges to provide natural drift fences. We used the taxonomic key in Rossman et al. (1996) to distinguish among Thamnophis species. We measured snout-vent length (SVL) to the nearest millimeter and mass to the nearest gram. Technicians were trained such that each individual snake was measured using the same methods. Although precise measurement of snakes to within one millimeter is problematic (Blouin-Demers, 2003), errors in measurement are random and unlikely to bias our conclusions. We determined individual sex with sexing probes. Each captured individual was implanted with a Passive Integrated Transponder (PIT) tag for permanent identification. After completion of all measurements and marking, individuals were released at the point of capture.

We estimated Giant Gartersnake abundance using standard mark-recapture techniques. To standardize results among sites, we only included individuals captured in traps to estimate abundance, and we condensed capture histories to weekly samples because of low daily capture probabilities. We fit Huggins' closed population models (Chao and Huggins 2005) representing constant (re)capture probability (p[1] c[]), different, but constant capture and recapture probabilities (p[1] c[1]), time-varying (re)capture probabilities $(\mathrm{p}[\mathrm{t}] \mathrm{c}[])$, time-varying capture and constant recapture probabilities $(\mathrm{p}[\mathrm{t}] \mathrm{c}[1])$, 
(re)capture probability varying by sex (p[sex] c[]), (re)capture probability varying by length $(\mathrm{p}[\mathrm{SVL}] \mathrm{c}[\mathrm{l})$, and additive and interactive models of sex and length with time $(\mathrm{p}[\mathrm{sex}+$ time] c[], p[SVL + time] c[], p[sex $\times$ time] c[], and $\mathrm{p}[\mathrm{SVL} \times$ time $] \mathrm{c}[\mathrm{l})$ using the package RMark (J. Laake, unpubl., 2008) in R 2.6.2 (R Development Core Team, unpubl., 2008). Only models with more than two captures per parameter were included in the model set for a given site. The best-fit model was selected using $\mathrm{AIC}_{c}$; model averaging was used if the $\mathrm{AIC}_{c}$ weight of the best-fit model was less than 0.95 (Burnham and Anderson 2002).

We used site abundance estimates to calculate density of the Giant Gartersnake at each site by two methods based upon different assumptions of passive sampling. The first method was based on the assumption that traps sampled an equal area of wetland habitat regardless of site or differences in snake behavior. For this method, we placed a 100-m buffer around each trap and calculated the sampled area as the area of wetland and aquatic habitats within the buffered zone at each site. Changing the size of the buffer did not alter qualitative patterns among sites, provided the buffer was not so small as to be discontinuous within traplines (10 $\mathrm{m}$ or less). Our second method of calculating density operated under the assumption that snake behavior, rather than characteristics of the traps, delimits the boundary of the population. For this method, we used radio telemetry to estimate the area of influence of the traps separately for each site. At each site, five to eight large individuals $(>200 \mathrm{~g})$ were selected for radio telemetry studies. These individuals were surgically implanted with radio transmitters (Model SI-2T, Holohil Systems, Ltd., Carp, Ontario, Canada) using standard techniques (Reinert and Cundall, 1982), and were returned to their capture location after an approximately two week recovery period. Each individual was located five days per week and its location was recorded using GPS with 3-5 m error. From the radio locations of individuals captured at each site, we calculated an effective trap boundary as the mean distance from the $95 \%$ isopleths of the kernel use distribution to the trap line in which the individual was originally captured. All trap lines at each site were then buffered by this effective trap boundary to calculate a sampled area. For the telemetry-based method, we did not eliminate upland habitats from the area calculation because tracked individuals were occasionally observed to travel across and use upland habitats. Regardless of the method used to calculate sampled area, we divided the abundance estimate by the sampled area at each site to estimate density.
Data from the first capture of each individual were used for morphological analyses. We examined biases in capture probability by capture method using a log-linear test of independence (Quinn and Keough, 2002). We examined sex ratios at each site using the binomial test. We examined sexual size dimorphism in SVL and mass by several methods. We used AIC to examine the fit of linear mixed models of the effect of sex on log-transformed SVL and mass, using site as a random effect. We also examined the degree of sexual size dimorphism at each site using the Sexual Dimorphism Index (SDI; Gibbons and Lovich, 1990) and bootstrapped confidence intervals for the index. We also examined differences in the relationship of length with mass between males and females using AIC with linear mixed models using site as a random effect. We cube-root transformed mass for this analysis under the assumption that mass scales with volume, rather than length, and to better meet the assumption of normally distributed residuals. Finally, we used $\mathrm{AIC}_{c}$ to examine the fit of linear models of the effect of sex and site on body condition. We defined a body condition index as the residuals of an $\ln$ (mass) $=\beta_{0}+\beta_{1} \ln (S V L)$ regression of all individuals, regardless of sex or site. We used R 2.6.2 (R Development Core Team, unpubl., 2008) for all statistical analyses.

\section{RESULTS}

We captured 103 Giant Gartersnakes at Badger Creek, 88 at Gilsizer Slough, 53 at Colusa NWR, and 164 at Natomas Basin (Table 1). For all sites but Colusa NWR, the best-fit model indicated time-varying capture probabilities but no effect of sex, size, or previous capture (Table 2). Models that included an additive effect of sex or SVL on time were not considered to be a good fit, because sex and SVL in these models were "pretending variables" (Anderson, 2008) that had little explanatory value. Therefore, we used the results of the time-varying capture probability model to estimate abundance at these sites. At Colusa NWR, evidence existed for recapture probability to be lower than initial capture probability (weekly initial capture probability $=0.102[95 \%$ $\mathrm{CI}=0.037-0.249]$, weekly recapture probability $=0.027[0.013-0.056])$, but two models indicated some evidence of fitting our data (sex and SVL were also pretending variables for Colusa NWR). Therefore, we used model averaging to estimate abundance at this site. Density varied by the method used to estimate sampled area, but qualitative patterns were similar for both methods (Table 3). Using a fixed buffer, all sites had different densities, with Badger Creek 
TABLE 1. Trapping effort, counts, and abundance estimates for the Giant Gartersnake at four sites in the Sacramento Valley, California. Abundance estimates are derived from the best-fit Huggins closed-capture model for each site indicated in Table 2, except for Colusa NWR for which the abundance estimate is derived from model-averaging. Numbers in parenthesis are $95 \%$ confidence intervals.

\begin{tabular}{lccccc}
\hline \hline \multicolumn{1}{c}{ Site } & Trap days & Total captured individuals & Trapped individuals & Number tracked & Abundance \\
\hline Badger Creek & 18,376 & 103 & 103 & 5 & $118(111-132)$ \\
Gilsizer Slough & 17,136 & 88 & 67 & 8 & $177(124-280)$ \\
Colusa NWR & 12,198 & 53 & 22 & 6 & $29(22-53)$ \\
Natomas Basin & 19,170 & 164 & 141 & 6 & $229(199-276)$ \\
\hline
\end{tabular}

having the greatest density, followed by Gilsizer Slough, Natomas Basin, and Colusa NWR (Table 3). Using snake behavior to delimit the population boundary again resulted in Badger Creek having the greatest density, with no detectable difference between Gilsizer Slough and Natomas Basin, which both had greater density than Colusa NWR (Table 3).

Sex ratios were similar among sites. Evidence for bias in capture probabilities by capture

TABLE 2. Fit of Huggins' closed population models for Badger Creek, Gilsizer Slough, Colusa National Wildlife Refuge, and the Natomas Basin. For models, $\mathrm{p}=$ capture probability, c $=$ recapture probability, (1) indicates a constant parameter value, and $\mathrm{c}()$ indicates that recapture probability is equal to capture probability. Models are listed in order of decreasing support for each site.

\begin{tabular}{|c|c|c|c|c|c|c|}
\hline Site & Model & Deviance & No. Param. & $\mathrm{AIC}_{c}$ & $\triangle \mathrm{AIC}_{c}$ & Weight \\
\hline \multirow[t]{10}{*}{ Badger Creek } & $\mathrm{p}$ (time) $\mathrm{c}()$ & $1,463.5$ & 30 & $1,596.1$ & 0.0 & 0.53 \\
\hline & $\mathrm{p}(\mathrm{SVL}+$ time $) \mathrm{c}()$ & $1,534.8$ & 31 & $1,597.4$ & 1.4 & 0.27 \\
\hline & $\mathrm{p}($ sex + time $) \mathrm{c}()$ & $1,535.3$ & 31 & $1,597.9$ & 1.8 & 0.21 \\
\hline & $\mathrm{p}(1) \mathrm{c}(1)$ & $1,547.9$ & 2 & $1,623.8$ & 27.7 & 0.00 \\
\hline & $\mathrm{p}(1) \mathrm{c}()$ & $1,551.1$ & 1 & $1,625.0$ & 28.9 & 0.00 \\
\hline & $\mathrm{p}($ sex $\times$ time $) \mathrm{c}()$ & $1,503.3$ & 60 & $1,625.7$ & 29.7 & 0.00 \\
\hline & $\mathrm{p}(\mathrm{SVL}) \mathrm{c}()$ & $1,622.4$ & 2 & $1,626.4$ & 30.3 & 0.00 \\
\hline & $\mathrm{p}(\operatorname{sex}) \mathrm{c}()$ & $1,622.8$ & 2 & $1,626.8$ & 30.7 & 0.00 \\
\hline & $\mathrm{p}$ (time) $\mathrm{c}(1)$ & $1,494.5$ & 31 & $1,629.0$ & 33.0 & 0.00 \\
\hline & $\mathrm{p}(\mathrm{SVL} \times$ time $) \mathrm{c}()$ & $1,517.2$ & 60 & $1,639.6$ & 43.5 & 0.00 \\
\hline \multirow[t]{10}{*}{ Gilsizer Slough } & $\mathrm{p}$ (time) $\mathrm{c}()$ & 489.8 & 17 & 467.4 & 0.0 & 0.54 \\
\hline & $\mathrm{p}(\mathrm{SVL}+$ time $) \mathrm{c}()$ & 432.3 & 18 & 468.9 & 1.5 & 0.25 \\
\hline & $\mathrm{p}($ sex + time $) \mathrm{c}()$ & 432.7 & 18 & 469.3 & 1.9 & 0.21 \\
\hline & $\mathrm{p}(\mathrm{SVL} \times$ time $) \mathrm{c}()$ & 414.8 & 34 & 484.9 & 17.5 & 0.00 \\
\hline & $\mathrm{p}$ (time) $\mathrm{c}(1)$ & 507.4 & 18 & 487.1 & 19.7 & 0.00 \\
\hline & $\mathrm{p}($ sex $\times$ time $) \mathrm{c}()$ & 423.9 & 34 & 494.1 & 26.7 & 0.00 \\
\hline & $p(1) c()$ & 574.6 & 1 & 519.7 & 52.3 & 0.00 \\
\hline & $\mathrm{p}(\mathrm{SVL}) \mathrm{c}($ ) & 517.2 & 2 & 521.2 & 53.8 & 0.00 \\
\hline & $\mathrm{p}(1) \mathrm{c}(1)$ & 574.4 & 2 & 521.5 & 54.1 & 0.00 \\
\hline & $\mathrm{p}(\operatorname{sex}) \mathrm{c}()$ & 517.6 & 2 & 521.6 & 54.2 & 0.00 \\
\hline Colusa National Wildlife & $\mathrm{p}(1) \mathrm{c}(1)$ & 185.7 & 2 & 189.2 & 0.0 & 0.77 \\
\hline \multirow[t]{7}{*}{ Refuge } & $\mathrm{p}(1) \mathrm{c}()$ & 191.3 & 1 & 192.9 & 3.7 & 0.12 \\
\hline & $\mathrm{p}(\mathrm{SVL}) \mathrm{c}()$ & 190.8 & 2 & 194.9 & 5.7 & 0.05 \\
\hline & $\mathrm{p}(\operatorname{sex}) \mathrm{c}()$ & 190.9 & 2 & 194.9 & 5.7 & 0.05 \\
\hline & $\mathrm{p}$ (time) $\mathrm{c}(1)$ & 156.7 & 20 & 198.3 & 9.1 & $<0.01$ \\
\hline & $\mathrm{p}$ (time) $\mathrm{c}()$ & 160.9 & 19 & 200.3 & 11.1 & $<0.01$ \\
\hline & $\mathrm{p}(\mathrm{SVL}+$ time $) \mathrm{c}()$ & 160.4 & 20 & 202.5 & 13.3 & $<0.01$ \\
\hline & $\mathrm{p}($ sex + time $) \mathrm{c}()$ & 160.4 & 20 & 202.5 & 13.3 & $<0.01$ \\
\hline \multirow[t]{10}{*}{ Natomas Basin } & $\mathrm{p}$ (time) $\mathrm{c}()$ & $1,384.7$ & 19 & $1,314.6$ & 0.0 & 0.47 \\
\hline & $\mathrm{p}(\mathrm{SVL}+$ time) $\mathrm{c}()$ & $1,275.1$ & 20 & $1,315.4$ & 0.8 & 0.31 \\
\hline & $\mathrm{p}($ sex + time $) \mathrm{c}()$ & $1,275.7$ & 20 & $1,316.1$ & 1.5 & 0.23 \\
\hline & $\mathrm{p}$ (time) $\mathrm{c}(1)$ & $1,401.6$ & 20 & $1,333.5$ & 18.9 & 0.00 \\
\hline & $\mathrm{p}(\mathrm{SVL} \times$ time $) \mathrm{c}()$ & $1,256.7$ & 38 & $1,333.9$ & 19.3 & 0.00 \\
\hline & $\mathrm{p}($ sex $\times$ time $) \mathrm{c}()$ & $1,261.4$ & 38 & $1,338.5$ & 23.9 & 0.00 \\
\hline & $\mathrm{p}(1) \mathrm{c}(1)$ & $1,486.0$ & 2 & $1,381.7$ & 67.1 & 0.00 \\
\hline & $\mathrm{p}(1) \mathrm{c}()$ & $1,491.9$ & 1 & $1,385.6$ & 71.0 & 0.00 \\
\hline & $\mathrm{p}(\mathrm{SVL}) \mathrm{c}()$ & $1,382.4$ & 2 & $1,386.4$ & 71.8 & 0.00 \\
\hline & $\mathrm{p}(\operatorname{sex}) \mathrm{c}()$ & $1,383.0$ & 2 & $1,387.0$ & 72.4 & 0.00 \\
\hline
\end{tabular}


Table 3. Density estimates for the Giant Gartersnake at four sites in the Sacramento Valley, California, calculated by two different methods. Density estimates are based upon abundances estimated in Table 1 . For the fixed buffer estimate, the buffer was equal for each site and sampled area was measured by buffering each trap by $100 \mathrm{~m}$. Nonwetland habitats were removed from the sampled area calculation. For the telemetry-based buffer, the buffer was estimated as the distance from the trap line to the mean 95\% isopleth of the kernel use distribution of radio-tracked individuals at each site, and sampled area was calculated by buffering the trap line by this distance, regardless of habitat type. Numbers in parenthesis are $95 \%$ confidence intervals.

\begin{tabular}{llccc}
\hline \hline \multicolumn{1}{c}{ Method } & \multicolumn{1}{c}{ Site } & Buffer (m) & Sampled area (ha) & Density (ind./ha) \\
\hline Fixed buffer & Badger Creek & 100 & 15 & $8.0(7.6-9.0)$ \\
& Gilsizer Slough & 100 & 57 & $3.1(2.2-4.9)$ \\
& Colusa NWR & 100 & 35 & $0.83(0.63-1.5)$ \\
Telemetry-based buffer & Natomas Basin & 100 & 133 & $1.7(1.5-2.1)$ \\
& Badger Creek & 210 & 62 & $1.9(1.8-2.1)$ \\
& Gilsizer Slough & 282 & 296 & $0.60(0.42-0.95)$ \\
& Colusa NWR & 400 & 175 & $0.17(0.13-0.30)$ \\
& Natomas Basin & 122 & 304 & $0.75(0.65-0.91)$ \\
\hline
\end{tabular}

method and sex existed $\left(\mathrm{G}^{2}=3.78, \mathrm{df}=1, P=\right.$ $0.052)$; this bias was caused by a greater proportion of female captures than male captures by hand ( 47 female hand captures, 26 male hand captures). No evidence existed for different capture probabilities for each sex in traps (Table 2); therefore, we examined sex ratios using only data from individuals captured in traps. The sex ratio did not differ significantly from 1:1 at any site (Badger Creek sex ratio = 0.87 [95\% CI $=0.54-1.87]$, Gilsizer Slough $=$ 1.23 [0.74-2.07], Colusa NWR $=1.44$ [0.57-3.83], Natomas Basin $=0.83$ [0.59-1.17]).

Female Giant Gartersnakes were larger than males, and allometry differed between the sexes. Females were longer (female log-normal mean SVL $=692 \mathrm{~mm}, 95 \% \mathrm{CI}=(377-1168)$; male $=581$ (387-839); Fig. 2) and heavier (female log-normal mean mass $=250,95 \% \mathrm{CI}$ $=(24-1030) ;$ male = 101 (26-274); Fig. 3) than males (Table 4). Site explained little of the variation in SVL (site variance $=0.0025$, residual variance $=0.061$ ) or mass (site variance $=0.0082$, residual variance $=0.65$ ). The SDI was significantly greater than one at all sites (Badger Creek $=1.15$, bootstrapped $P<0.001$; Colusa NWR $=1.18, P<0.001$; Gilsizer Slough $=1.10$, $P<0.05$; Natomas Basin $=1.27, P<0.001$ ). Males and females less than approximately $500 \mathrm{~mm}$ SVL have similar masses for the same SVL, but female mass increases more rapidly with length than male mass (Table 5, Fig. 4). Although the greatest difference in body condition was between the sexes, body condition also varied among sites (Table 6). When controlling for body condition differences between the sexes, individuals at Badger Creek and Gilsizer had significantly greater body condition than individuals at Colusa NWR (Fig. 5).

\section{DisCUSSION}

The density of the Giant Gartersnake was quite variable among sites, and the observed pattern of densities largely agreed with our expectations. Unfortunately, density estimates for the Giant Gartersnake prior to the loss of 1.4 million ha of wetlands in the Central Valley between the 1850s and mid-1980s (Frayer et al., 1989) are not available; thus, we cannot compare our results to presettlement populations. Nonetheless, describing contemporary densities is an important task, and provides a benchmark for measurement of future population changes. As we hypothesized, density was greatest at Badger Creek, a natural wetland likely representative of the habitats in which the Giant Gartersnake evolved. The two sites with intermediate density, Gilsizer Slough and Natomas Basin, were dominated by rice agriculture. In California, rice fields are flooded in late April or May and maintain water for most of the Giant Gartersnake active season (until September). When rice becomes emergent in June, the rice fields become shallow marsh habitat suitable for the Giant Gartersnake. Canals associated with rice agriculture typically provide a reliable source of aquatic habitat throughout the year. Although Giant Gartersnake densities were lower in areas dominated by rice agriculture than natural wetlands, it appears that the Giant Gartersnake can persist in these habitats. The site with the lowest Giant Gartersnake density, Colusa NWR, was managed primarily for wintering waterfowl habitat. In the Sacramento Valley, waterfowl management typically involves raising food crops during the summer and flooding these fields for overwintering waterfowl. Seasonal wetlands on Colusa NWR were typically flooded in the winter, when 


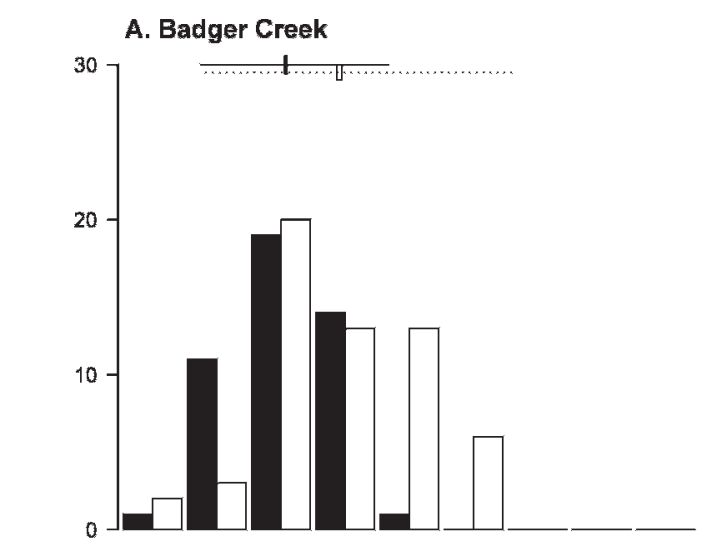

\section{B. Colusa NWR}

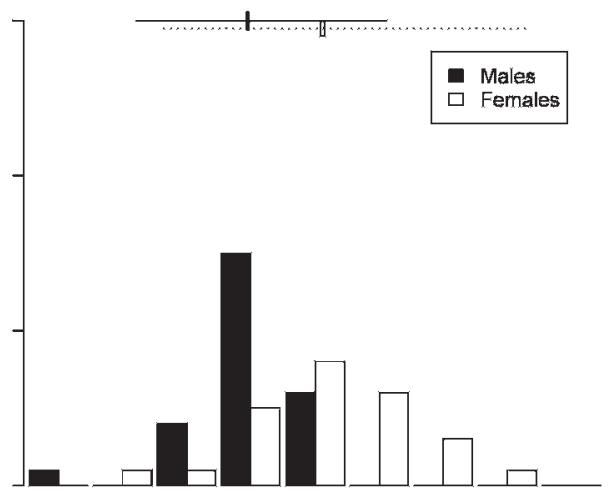

D. Natomas Basin

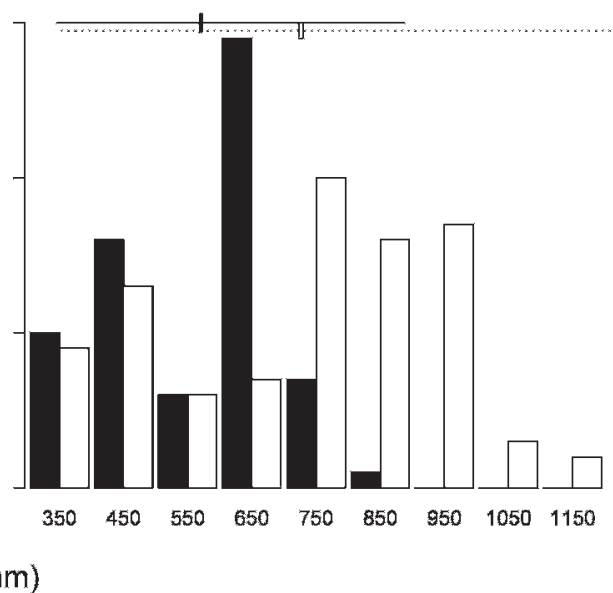

FIG. 2. Distribution of male and female snout-vent length (SVL) at four sites in the Sacramento Valley, California. Small vertical bars and horizontal lines near the top of each plot represent the log-normal mean and 95\% confidence interval, respectively, for males (black bar, solid line) and females (hollow bar, dotted line) at that site.

snakes were hibernating and, therefore, did not provide the aquatic foraging habitat required by the Giant Gartersnake. Large home ranges (and, thus, large sampled area) at Colusa NWR were caused by the movement of individuals away from the refuge and into surrounding rice fields as refuge canals dried. This movement away from the refuge also was the likely mechanism for the lower recapture probabilities of individuals at Colusa NWR. Maintaining aquatic habitats with emergent vegetation on wildlife refuges during the summer would greatly increase the quality of refuges as habitat for the Giant Gartersnake. Although our small sample of sites prohibits inference to Giant Gartersnake populations in other wetlands or wildlife refuges, our results suggest that permanent wetlands with emergent vegetation harbor the greatest densities of the Giant
Gartersnake and that wetlands that do not provide water during the active season (April to October) of the Giant Gartersnake cannot support large populations of this aquatic snake.

Further evidence to support our hypothesis that natural emergent wetlands are high quality Giant Gartersnake habitat is provided by our analysis of body condition. Badger Creek and Gilsizer Slough had the greatest densities of the Giant Gartersnake, and individuals at these sites also had the greatest body condition. Although temporal differences in body condition might exist, sites with high and low condition (Badger Creek and Colusa NWR, respectively) were sampled concurrently. Although population vital rates, such as survival and recruitment, are required to definitively assess habitat quality for a species (Van Horne, 1983), observing both greater densities and 
A. Badger Creek

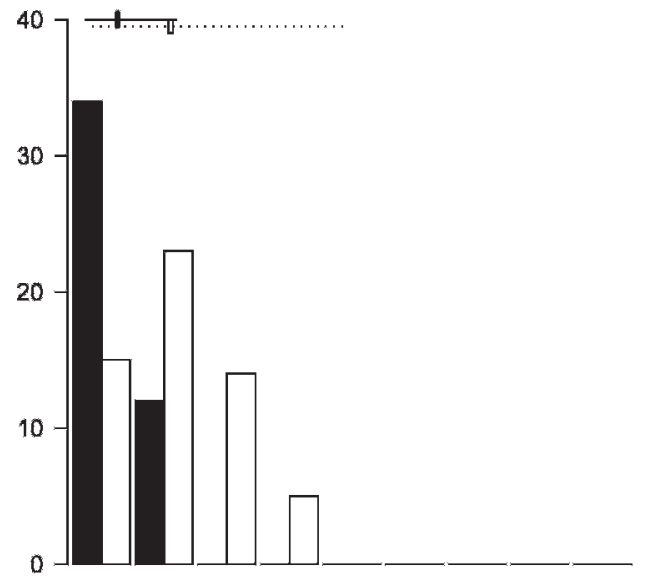

C. Gilsizer Slough

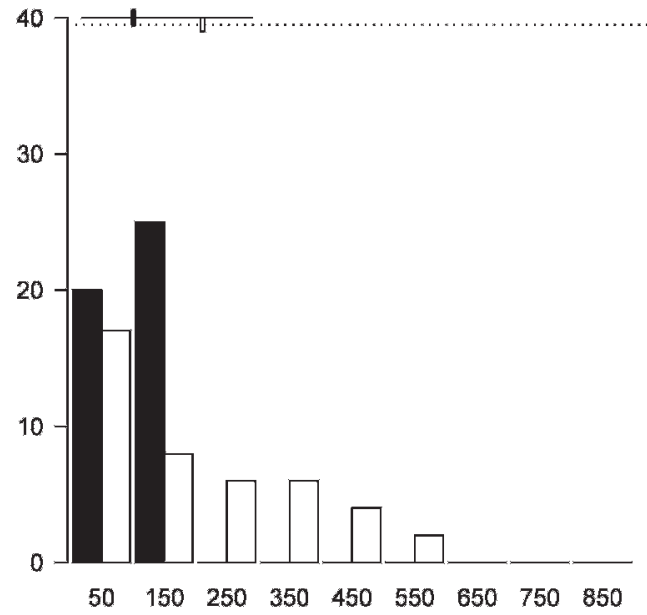

\section{B. Colusa NWR}

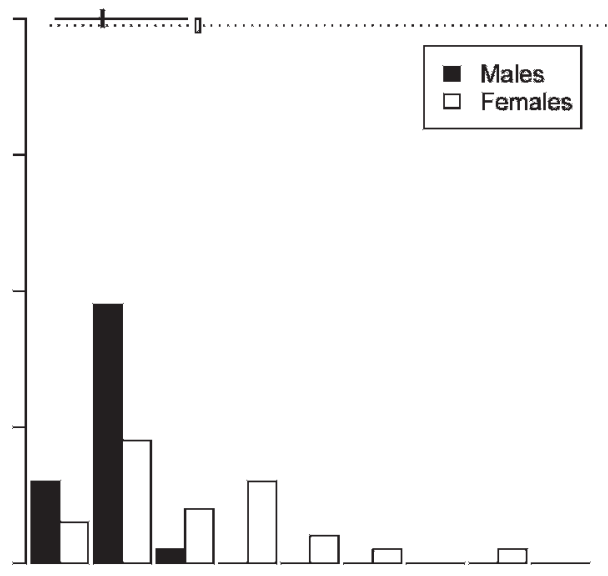

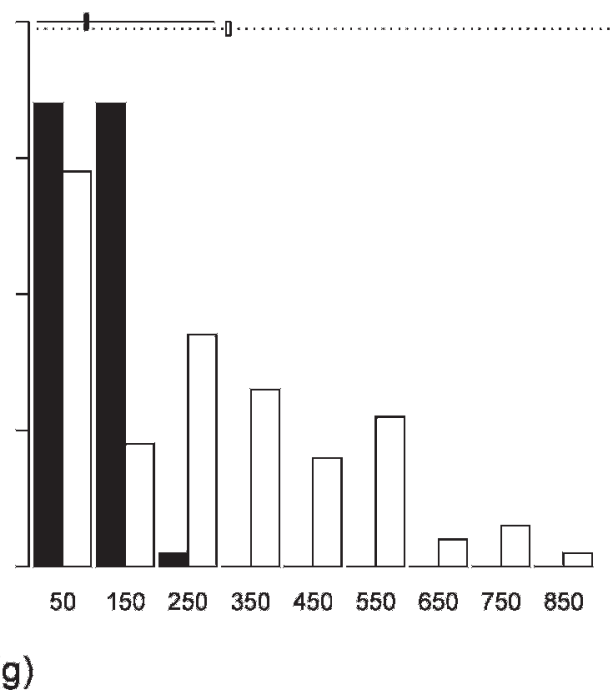

FIG. 3. Distribution of male and female mass at four sites in the Sacramento Valley, California. Small vertical bars and horizontal lines near the top of each plot represent the log-normal mean and 95\% confidence interval, respectively, for males (black bar, solid line) and females (hollow bar, dotted line) at that site.

greater body condition at the same sites suggests that these sites are of greater quality. The coincidence of density and body condition also suggests that studied populations of the Giant Gartersnake associated with natural wet- lands are not prey limited and that these highquality sites could possibly support larger populations. If the differences among sites are driven by habitat or disturbance, our results also suggest that habitat restoration and man-

TABLE 4. Fit of linear mixed models examining size differences between male and female Giant Gartersnakes. All models include site as a random effect. int $=$ intercept.

\begin{tabular}{lcccrrc}
\hline \hline Measure & Model & Deviance & No. Param. & \multicolumn{1}{c}{ AIC } & \multicolumn{1}{c}{ AIC } & Weight \\
\hline SVL & $\log ($ SVL) $=$ int + sex & 21.8 & 3 & 27.8 & 0.0 & 1.00 \\
& $\log ($ SVL) $=$ int & 58.9 & 2 & 62.9 & 35.1 & 0.00 \\
Mass & $\log$ (mass) $=$ int + sex & 977 & 3 & 983.1 & 0.0 & 1.00 \\
& $\log ($ mass $)=$ int & 1034 & 2 & 1037.8 & 54.7 & 0.00 \\
\hline
\end{tabular}


TABLE 5. Fit of linear mixed models examining allometry differences between male and female Giant Gartersnakes. Site was included as a random effect in all models. All models include an intercept.

\begin{tabular}{cccccc}
\hline \hline Model & Deviance & No. Param. & AIC & \multicolumn{1}{c}{$\triangle$ AIC } & Weight \\
\hline$\sqrt[3]{\text { mass }}=S V L \times$ sex & 195.6 & 5 & 205.6 & 0.0 & 1.00 \\
$\sqrt[3]{\text { mass }}=S V L+$ sex & 212.5 & 4 & 220.5 & 14.9 & 0.00 \\
$\sqrt[3]{\text { mass }}=S V L$ & 264.6 & 3 & 270.6 & 65.0 & 0.00 \\
\hline
\end{tabular}

agement might be a very effective tool for Giant Gartersnake conservation.

Sex ratios of the Giant Gartersnake appear unbiased. Based upon trap data, the sex ratio in all sampled Giant Gartersnake populations is indistinguishable from $1: 1$ and is similar to other Thamnophis species (Rossman et al., 1996). Traps sampled both sexes equally, but females make up a greater proportion of hand-captured individuals than males. Females may have a higher probability of hand capture because they grow to be large and are more visible than males. Female behavior may also influence their probability of visual detection and capture if gravid females tend to bask more than males to enhance development of embryos (Lillywhite, 1987; Charland, 1995; Isaac and Gregory, 2004). We found that female Giant Gartersnakes were larger on average than males, a result consistent with the majority of studies of ophidian species (Shine, 1978, 1994; Fitch, 1981). The degree of sexual size dimorphism in the Giant Gartersnake is over twice the level $(8.5 \%)$ reported by Shine (1991) in a review of 230 colubrid species. Similarly large levels of sexual size dimorphism have been noted in other aquatic snake species (Fitch, 1981; Shine, 1986). Although males and

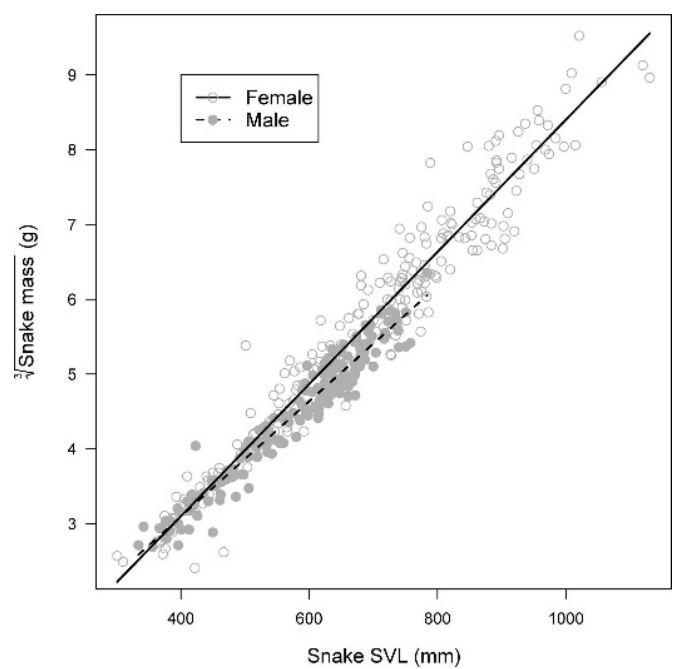

FIG. 4. Cube-root mass as a function of snout-vent length (SVL) for Giant Gartersnake males and females. females begin life at a similar length and mass, longer females gain mass at a greater rate than males. This difference in allometry results in females having greater body condition than males.

The method by which we determined the area sampled at each site had little qualitative effect on patterns of density among sites, but the differences in absolute density were sometimes large. The basic difficulty we encountered was determining the geographic limits of the sampled population. Defining area based upon the traps and restricting the definition of sampled area to habitats that could be sampled by our method partially overcomes problems associated with estimating density across habitat types (Carpenter, 1952). By using telemetry to define the population boundary, we partially overcame problems associated with geographic closure of the population and temporary emigration, because sampled individuals defined the geographic limits of the population. Estimating absolute density and comparing density across studies are problematic in most field situations because of habitat heterogeneity and temporary emigration of individuals. Bayesian hierarchical models for jointly estimating effective sampled area and density (Royle and Young, 2008) appear a promising solution to the latter problem.

Our results should be regarded as baseline information on the status of the Giant Gartersnake in the Sacramento Valley. These data can be used to assess the effects of recovery efforts or future land use changes on these populations. For example, Colusa NWR was traditionally managed for seasonal marshes that dried up in summer during the period of Giant Gartersnake reproduction. Following our studies of the Giant Gartersnake, the Colusa NWR acquired additional land in 1998, where in the winter of 1999-2000, permanent wetlands were created and managed to emphasize benefits for the local Giant Gartersnake population. Assessment of current and future Giant Gartersnake densities at Colusa NWR can be compared to 1997 premanagement densities to evaluate habitat restoration and management for this species. Similarly, land is being acquired and habitat created and managed for the Giant 
TABLE 6. Fit of linear models examining differences in Giant Gartersnake body condition by sex and site. All models include an intercept. BCI = residuals of an $\ln ($ mass $)=\beta_{0}+\beta_{1} \ln (S V L)$ regression on the first capture of individuals pooled across sites.

\begin{tabular}{lccccc}
\hline \hline \multicolumn{1}{c}{ Model } & Deviance & No. Param. & $\mathrm{AIC}_{c}$ & $\triangle \mathrm{AIC}_{c}$ & Weight \\
\hline $\mathrm{BCI}=$ sex + site & -233.6 & 5 & -223.5 & 0.0 & 1.00 \\
$\mathrm{BCI}=$ sex & -210.9 & 2 & -206.9 & 16.5 & 0.00 \\
$\mathrm{BCI}=$ site & -185.5 & 4 & -177.4 & 46.0 & 0.00 \\
$\mathrm{BCI}=$ null & -165.1 & 1 & -163.1 & 60.4 & 0.00 \\
\hline
\end{tabular}

Gartersnake at Gilsizer Slough and the Natomas Basin as mitigation for development. The results of our study suggest that recovery efforts for the Giant Gartersnake in these and other locales should use the permanent wetlands of Badger Creek as a model for habitat restoration and creation to recover this species.

Acknowledgments.-We are grateful for the help provided to us by T. Graham and the late G. Hansen in beginning our studies. We thank the U.S. Fish and Wildlife Service and the U.S. Bureau of Reclamation representatives on the Central Valley Project Improvement Act b1(other) Committee for helping to fund this research. We are indebted to P. Gore for administrative support, L. Martin for data management, C. Overton for assistance in home-range analyses, and the many biologists who collected the data for this project. Snakes were handled in accordance with the University of California, Davis, Animal Care and Use Protocol 9699 and as

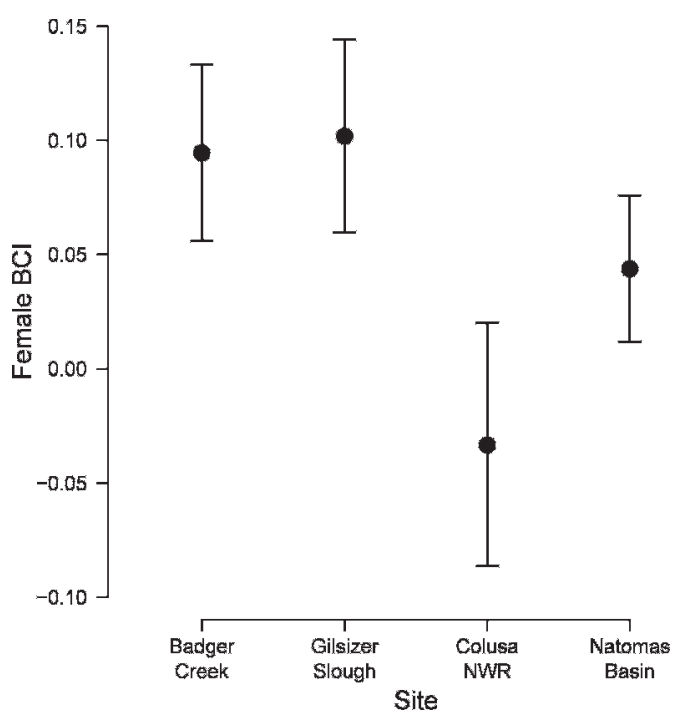

FIG. 5. Body condition index (BCI; defined as the residuals of an $\ln$ (mass) $=\beta_{0}+\beta_{1} \ln (S V L)$ regression) of females at each of the four study sites. The circle indicates the mean $\mathrm{BCI}$ for females at each site, and error bars indicate $95 \%$ confidence intervals. stipulated in U.S. Fish and Wildlife Service Recovery Permit TE-020548-5. Any use of trade, product, or firm names in this publication is for descriptive purposes only and does not imply endorsement by the U.S. government.

\section{Literature Cited}

Anderson, D. R. 2008. Model Based Inference in the Life Sciences: A Primer on Evidence. Springer, New York.

Blouin-Demers, G. 2003. Precision and accuracy of body-size measurements in a constricting, largebodied snake (Elaphe obsoleta). Herpetological Review 34:320-323.

Burnham, K. P., And D. R. Anderson. 2002. Model Selection and Multimodel Inference: A Practical Information-Theoretic Approach. 2nd ed. Springer, New York.

Carpenter, C. C. 1952. Comparative ecology of the Common Garter Snake (Thamnophis s. sirtalis), the Ribbon Snake (Thamnophis s. sauritus), and Butler's Gartersnake (Thamnophis butleri) in mixed populations. Ecological Monographs 22:236-258.

Casazza, M. C., G. D. Wylie, and C. J. Gregory. 2000. A funnel trap modification for surface collection of aquatic amphibians and reptiles. Herpetological Review 31:91-92.

ChaO, A., and R. M. Huggins. 2005. Modern closedpopulation capture-recapture models. In S. C. Amstrup, T. L. McDonald, and B. F. J. Manly (eds.), Handbook of Capture-Recapture Analysis, pp. 58-87. Princeton University Press, Princeton, NJ.

Charland, M. B. 1995. Thermal consequences of reptian viviparity-thermoregulation in gravid and nongravid garter snakes (Thamnophis). Journal of Herpetology 29:383-390.

Fiтch, H. S. 1940. A biogeographical study of the ordinoides Artenkreis of garter snakes (genus Thamnophis). University of California Publications in Zoology 44:1-150.

— . 1981. Sexual size differences in reptiles. Miscellaneous Publications of the Museum of Natural History the University of Kansas 70:1-72.

Frayer, W. E., D. D. Peters, and H. R. Pywell. 1989. Wetlands of the California Central Valley status and trends. U.S. Fish and Wildlife Service, Portland, OR.

Gibbons, J. W., And J. E. Lovich. 1990. Sexual dimorphism in turtles with emphasis on the Slider Turtle (Trachemys scripta). Herpetological Monographs 4:1-29. 
Hansen, G. E., And J. M. Brode. 1980. Status of the Giant Garter Snake, Thamnophis gigas (Fitch). California Department of Fish and Game. Inland Fisheries Endangered Species Program Special Publication Report Number 80-5, Sacramento.

IsAac, L. A., AND P. T. Gregory. 2004. Thermoregulatory behaviour of gravid and non-gravid female Grass Snakes (Natrix natrix) in a thermally limiting high-latitude environment. Journal of Zoology 264:403-409.

Lillywhite, H. B. 1987. Temperature, energetics, and physiological ecology. In R. A. Seigel, J. T. Collins, and S. S. Novak (eds.), Snakes: Ecology and Evolutionary Biology, pp. 422-477. Blackburn Press, Caldwell, NJ.

Mazerolle, M. J., L. L. Bailey, W. L. Kendall, J. A. Royle, S. J. Converse, AND J. D. Nichols. 2007. Making great leaps forward: accounting for detectability in herpetological field studies. Journal of Herpetology 41:672-689.

Parker, W. S., and M. V. Plummer. 1987. Population ecology. In R. A. Seigel, J. T. Collins, and S. S. Novak (eds.), Snakes: Ecology and Evolutionary Biology, pp. 253-301. Blackburn Press, Caldwell, NJ.

QuinN, G. P., AND M. J. KeOUGH. 2002. Experimental Design and Data Analysis for Biologists. Cambridge University Press, Cambridge.

Reinert, H., and D. Cundall. 1982. An improved surgical implantation method for radio-tracking snakes. Copeia 1982:702-705.
Rossman, D. A., N. B. Ford, and R. A. Seigel. 1996. The Garter Snakes: Evolution and Ecology. University of Oklahoma Press, Norman.

Royle, J. A., And K. V. Young. 2008. A hierarchical model for spatial capture-recapture data. Ecology 89:2281-2289.

SHINe, R. 1978. Sexual size dimorphism and male combat in snakes. Oecologia 33:269-278.

1986. Sexual differences in morphology and niche utilization in an aquatic snake, Acrochordus arafurae. Oecologia 69:260-267.

. 1991. Intersexual dietary divergence and the evolution of sexual dimorphism in snakes. American Naturalist 138:103-122.

_- 1994. Sexual size dimorphism in snakes revisited. Copeia 1994:326-346.

U.S. Fish and Wildlife SERvice. 1993. Endangered and threatened wildlife and plants: determination of threatened status for the Giant Garter Snake. Federal Register 58:54053-54066.

1999. Draft recovery plan for the Giant Gartersnake (Thamnophis gigas). U.S. Fish and Wildlife Service, Portland, OR.

VAn Horne, B. 1983. Density as a misleading indicator of habitat quality. Journal of Wildlife Management 47:893-901.

Accepted: 6 May 2009. 